\title{
Creating High-Frequency, Naturalistic Opportunities to Develop Small Talk Skills in EFL Classrooms
}

\author{
Irina Kuznetsova \\ Udmurt State University
}

\begin{abstract}
Correspondence concerning this article should be addressed to Irina Kuznetsova, Department of Translation and Applied Linguistics, Udmurt State University, Universitetskaya St., bld. 1, Izhevsk, Russian Federation, 426034. E-mail:irina_kolodkina@yahoo.com
\end{abstract}

\begin{abstract}
The paper is the outcome of an action research project that investigated factors that keep students from participating in classroom small talk (ST). In-class observations, surveys and students' logs, backed by the author's self-reflection resulted in an intervention plan which aimed to help students with their anxiety and ST apprehension. The final role plays, as well as the survey demonstrated that there was a change in how the students noticed and used the opportunities to utilize ST. Specifically, they started to see the potential of classroom talk for putting ST skills into practice. Another finding is the need to raise the students' awareness of ST as a social and linguistic skill, to clearly establish ground rules for practising ST, and to create high-frequency, naturalistic opportunities to develop ST in class. It is argued in the paper that ST skills can be practised in the classroom beyond the purposefully designed activities, i.e. in spontaneous interactions between the teacher and the students. Such interactions may decrease the students' anxieties and reluctance to get engaged in small talk. This change would have a positive effect on their outside-the-classroom interactions in English, both in academic and work-place situations.
\end{abstract}

Keywords: small talk, EFL classroom talk, small talk strategies, action research

Small talk (ST) is often metaphorically described in reference to its pragmatic function. In literature, ST is often referred to as the 'gift of the gab' (Baber, 1991), which is necessary to 'oil the social wheels' (Holmes, 2005 ) or to 'break the ice' (Fine, 2005). There is a focus on the balanced 'ping-pong' nature of a natural, polite conversation (Fleming, 2013), and the importance of showing interest in others.

While these metaphors emphasize ST's importance, it turned out to be difficult to locate a distinct ST definition within an EFL context. And yet, within the communicative language teaching (CLT) paradigm, there is an expectation that a teacher will provide opportunities for learners to be engaged in interaction and meaningful communication while experimenting with the language (Richards, 2006).

For the ST practice, this CLT principle is translated into setting some specially designed communicative contexts such as reading ST episodes, acting them out, or role playing ST in prescribed situations. While this is certainly a valid approach to practising talk as interaction, such activities can hardly take place in each class. It seems that there are other, regular opportunities in class to practise ST in a meaningful way. Specifically, classroom talk can be used to enhance students' ST practice.

For the purposes of this study classroom $S T$ is defined as a social interaction between the students and the instructor that aims to build rapport. In many institutions EFL teachers do not make classroom ST at all. This observation resonates with the literature review: the methodology and pedagogical implications of making spontaneous ST with the group have not been explicitly researched. This action research project was started in order to check the initial assumption that classroom ST can improve students' attitudes about ST. The project should interest those teachers who are open to experimenting with their formal classroom talk and who seek new opportunities to encourage their students to make ST in class. 


\section{Materials and Methods}

\section{Literature Review}

ST may be valued in many social situations. In native English-speaking cultures, it is generally considered to be a learnable and transferable skill, so many communication experts turn their research into practical guidebooks, aimed specifically at native speakers of English (Baber, 1991; Carducci, 1999; Fine, 2005). Even a brief acquaintance with these books shows that they are written to address people's anxiety and reluctance to engage in ST. While ST may stir up panic even in a native speaker of English, it is only natural that making ST in English is quite a challenge for foreign language learners of English. Specifically, there are a lot of case studies describing how international students find it extremely hard to present a good image of themselves, partially because they lack such skills and dread social functions within and outside their host university (The Higher Education Academy, n.d.). The inability to establish and maintain relationships ultimately deprives these students of opportunities to become integrated into the community without a great deal of stress. Consequently, rapport building is an essential language skill for foreign students to develop (Bamford, 2008).

Since ST is a problem for EFL students, it is natural to assume that this skill is also a special area of professional interest for English language educators. Primarily, this is a question of how Communicative Language Teaching (CLT) principles are applied in teaching ST. There is also a question of the time and the effort a teacher is willing to allocate to practising ST.

CLT theory highlights the necessity to look at the language classroom as preparation for survival and effective performance in the real world (Jacobs \& Farrell, 2001; Littlewood, 1981; Richards, 2008). In most sources reviewed, this purpose, when considered in the context of teaching ST, gets translated into two major themes: the social nature of language usage (e.g., greetings, jokes, closings) and students' career considerations. Specifically, many English for Specific Purposes studies examine how to make effective ST at different work-place situations (pre-meeting talks, elevator talks, hallway talks, lunch talks, off-task talks, etc.). A number of EFL researchers focus on the content, distribution, and social functions of ST, as well as the consequences of failed ST (Bayles, 2009; Coupland, 2003; Holmes, 2005; Koaster, 2010; Mehus, 2004; Mirivel \& Tracy, 2005).

According to Fine (2005), in a person's daily life, ST incidents happen at least a dozen times a day. For some people these statistics mean a dozen of stimulating, meaningful casual conversations, while for others a dozen of uncomfortable, failed exchanges.
In one of her studies, Holmes (2005) looked at challenges presented by ST for two specific groups: new immigrant workers from non-English-speaking backgrounds and native English-speaking workers with an intellectual disability. Holmes concluded that no matter how different these peoples' social situations were, the kinds of difficulties they faced in managing different aspects of social talk at work were surprisingly similar: they did not sustain ST long enough, they did not pull their weight in the ST exchange, and when a coworker engaged them in ST, they answered in monosyllables or non-verbally, allowing the topic to drop inappropriately quickly (p. 359).

In an attempt to address such problems, methodologists and practitioners alike have concentrated their efforts on compiling lists of ST situations (McCarthy, 2003; Ockenden, 1972; Richards, 2006), on pragmatic considerations for these routines (Barron \& Schneider, 2009; Edwards \& Csizer, 2004; Schneider, 2008; Tannen, 1984), and on designing practice activities. Such activities may include speaking exercises with an emphasis on reading and then role playing some ready-made conversational episodes and/or actually role playing some situations that ask for ST exchanges for a start (Hadfield, 1996; Sakamoto, 2010; Ur, 1992; Westcombe, 2009). The most common activities are role plays, where students try making ST in a variety of less structured speaking contexts, including: being at a party, standing in a line, doing a job interview, talking to a seatmate on a plane, or waiting for a payment to go through and chatting with the clerk. While all of these communicative situations are certainly in accord with CLT principles, it should be emphasized that such ST happens exclusively in an artificial practice environment. Such simulations are surely the case for most of ELT contexts, but it is reasonable to assume that ST skills can be put into practice that goes beyond the purposefully designed contexts and involves spontaneous interactions between the teacher and their students. If exercised on a regular basis, such ST interactions may decrease students' anxieties and reluctance to get engaged in ST. This change would have a positive effect on their outside-the-classroom interactions in English, both in academic and work-place situations.

First and foremost, it is necessary to check if this assumption is true for a local teaching context. So, the study started with a desire to maximize the opportunities for a group of students to use and practise ST inside an EFL classroom. The starting point was Luk's (2004) rigorous study of classroom ST, which involves "...interactions between the teachers and the students that are not intended for pedagogical purposes" (p. 118). Luk argues that there is a strong connection between the classroom talk and the effect it might have on the development of EFL students' 
communicative competence. The study emphasizes that English language teachers should attempt to open themselves up to more non-institutional talk contexts. For example, the researcher demonstrated how the teacher she observed made ST with the students who had completed the assignment while they were waiting for the others to finish (p. 122). The ultimate goal and benefit of such spontaneous interactions, Luk says, is for students and teachers alike to experience "the joy of using a foreign language for meaningful communication" (p. 129). While the researcher's interests lie in pedagogical implications of classroom ST, the study has serious implications for those English language educators who are interested in ST methodology. Primarily, it shows that authentic ST can indeed become a part of the classroom talk. If a teacher is willing to make ST in their class, it can make a world of difference in breaking away from the constraints of institutional classroom talk and, therefore, from the anxiety which seems to be associated with classroom ST. Anxiety and ST apprehension is what started this research study; so Luk's work turned out to be very helpful and strategic. Most importantly, Luk's research implicitly indicated the potential of taking a step away from an exclusive, activities-based approach to teaching ST, which seems to prevail in the contemporary methodology. With this study in mind, it was possible to see the potential of classroom talk for putting ST skills into practice.

To be clear, this paper is not arguing that the traditional ST practice is a faulty approach, but that rather than limit practicing ST within some specially designed activities, English language teachers should increase practice frequency through integrating ST into classroom talk, for example at the beginning stages of English classes. While the traditional frame of an English class starts from a greeting and then moves on to warm-ups (Ur, 2013), it will be demonstrated in this paper that making authentic teacher-students ST in between these two well-defined stages is natural, as well as effective. First of all, students get a chance to practise what they have learned in artificial ST practice activities in a different, but meaningful setting. Secondly, this natural interaction provides a rapport building opportunity between the teacher and their students, which, if effective, will make everyone feel comfortable for the whole class ahead.

\section{Research Questions}

When it comes to the topic of effective communication, most people will readily agree on the value of ST skills on many academic and work-place occasions. Consequently, in this study, the primary interest in integrating ST into the classroom talk was to create a positive atmosphere for the class ahead. In terms of lesson planning, it seems right to have an ST component right after the greeting and before a warmup activity. When this study was started, the students were aware of this class routine, but they seemed to have a hard time to get through this class stage. The responses to the teacher's questions/comments in most cases were very unenthusiastic. Very often, it was necessary to address individual students to get an answer to a question, which, pragmatically speaking, was of social nature and was meant to be answered on a voluntary basis.

This observation defined the utmost purpose of this research: to change the ST situation in class. The initial data and self-reflection motivated a general interest and a need to explore ST in its application to the language classroom and its socio-linguistic significance. As the research focus evolved, the research questions were narrowed to the following:

1. What factors keep a chosen group of intermediate students from participating in ST?

2. What teaching strategies should a teacher employ to increase students' participation in ST at the opening stages of the classes?

\section{Teaching Context}

The setting for this study was a class of intermediate students within a university professional program majoring in Translation Studies. The students were in their second year; there were six females and three males in the class, all aged 17-20. The class met four times a week for two hours each session. The course followed the Department's curriculum, which equally emphasized the development of such skills as reading, writing, listening, and speaking. While the curriculum specifies which course book should be used for this group, the requirements for activities and methodology are unspecified. So, in many cases a teacher makes her own decisions.

One of these decisions concerns how to teach speaking. For the chosen class, this was done in the frames set by Richards (2006), who distinguishes the following functions of speaking: 1) talk as interaction; 2) talk as transaction; and 3) talk as performance. While the course book emphasizes the development of the two last functions, there is nothing in the units about teaching speaking as interaction (ST, in particular). The conversations with the students indicated that their previous experience with learning English did not seem to have underlined this important aspect either.

\section{Data Collection and the Study Design}

The data collection started from in-class observations. The purpose of student-observation was to understand the student's SR behaviour, while self- 
observation was targeted at learning more about the teacher's communicative behaviour.

To register how the ST evolved, who the most active/inactive participants were, what preferred communication strategies in making ST were (if there were any), a digital voice recorder and reflective notes and drawing were used. Each time the teacher made some after-class reflective notes. This preliminary stage of the study took about four weeks and went along with the initial literature review and transcribing the episodes of ST. In the interest of obtaining useful data, a student survey was conducted to learn more about the students' attitudes about ST and their evaluation of their personal and the group's performance.

The data from the survey allowed to structure a whole-class discussion on ST of which I made notes. This discussion centered around the following topics: ST's pragmatic function, the differences between the cultures and the languages, and practical applications of this skill to social functioning and workplace considerations. The purpose behind this discussion was to change the overall skeptical and indifferent attitude to ST and get the students' commitment to the learning experience ahead.

Based on the literature review and the initial data collection and analysis efforts, a four-week intervention plan was developed (see Table 1). The plan is focused on the ST strategies listed in Table 2.

The post-intervention stage started with two ST role play activities. The students were divided into two groups, and each group was provided with a scenario for a role play: Tower Block and House Parties (Hadfield, 1996). These role plays require the students to socialize with their partners while solving a communicative task, so there are lots of opportunities for every student to utilize ST extensively while mixing with others. While the students of one group were role playing their parts, others were told to become 'flies on the wall'. The observers were asked to follow the assigned classmate unobtrusively and register his/her performance in ST in specially designed assessment grids. The special areas of interest were the following: the ST topics and the relevant strategies used.

In the next class after the role plays, the students were offered the survey, which they had at the beginning. Through bringing in the same survey, the hope was to see if the students themselves registered any changes, and what suggestions they had for further development of this area.

\section{Results}

All in all, 48 episodes of small talk were transcribed: 12 episodes - during the initial stage, 28 episodes from the intervention stage and 8 more episodes of
Table 1

Road map: The intervention stage

\begin{tabular}{ll}
\hline 1 & $\begin{array}{l}\text { to raise the students' awareness of the ST social importance } \\
\text { through a whole class discussion }\end{array}$ \\
\hline 2 & $\begin{array}{l}\text { to get the students' commitment to make an effort and take } \\
\text { a more self-aware attitude towards practicing ST in class }\end{array}$ \\
\hline 3 & $\begin{array}{l}\text { to provide models of ST episodes and analyze them for the } \\
\text { common topics and the strategies, which can help to sus- } \\
\text { tain ST }\end{array}$ \\
\hline 4 & $\begin{array}{l}\text { to create and constantly update the class' resource bank of } \\
\text { ST episodes (authentic texts, audio and video episodes) }\end{array}$ \\
\hline 5 & $\begin{array}{l}\text { to provide the students with opportunities to practise ST in } \\
\text { two ways: (1) specially designed activities; and (2) within } \\
\text { classroom talk with the teacher, at the beginning of each } \\
\text { class }\end{array}$ \\
\hline 6 & $\begin{array}{l}\text { to audio record, transcribe the classroom episodes of ST; } \\
\text { then, to analyze these episodes together with the students }\end{array}$ \\
\hline 7 & $\begin{array}{l}\text { to encourage the students' reflection on their progress and } \\
\text { performance in classroom ST situations through keeping } \\
\text { logs }\end{array}$ \\
\hline
\end{tabular}

Table 2

Strategies for managing small talk

\begin{tabular}{ll}
\hline Strategy & Comment about the strategy \\
\hline shadowing & $\begin{array}{l}\text { repeating a word or a short part of what you } \\
\text { have just heard to show interest }\end{array}$ \\
\hline $\begin{array}{l}\text { asking an extra } \\
\text { question }\end{array}$ & $\begin{array}{l}\text { clarifying the point or/and getting extra in- } \\
\text { formation about what you've just heard }\end{array}$ \\
\hline $\begin{array}{l}\text { commenting on } \\
\text { partner's words }\end{array}$ & $\begin{array}{l}\text { Acknowledging that you've been listening } \\
\text { and making some remarks about what your } \\
\text { partner has said: That's right/ great/ true..... }\end{array}$ \\
\hline
\end{tabular}

commenting on Initiating a conversation, inviting your partsomething from ner to step in. For example,

the actual, real- I've always thought this room is kind of life context stuffy...

verbalizing your agreement or disagreement

This strategy is not so much about finding who is right and who is wrong; this is more of an invitation to share anecdotes, views and ideas of the subject matter

complimenting These strategies are great starters for a and complaining casual conversation; they naturally lead on to conversation development and smooth flow.

classroom ST, which had taken place when the study was formally finished. These transcripts were analysed in order to single out some tendencies occurring in the data: the length of silences, the participants in the episodes, the number of exchanges, and the preferred communicative strategies as they are outlined above, in Table 2.

The student responses were tabulated to the quantifiable survey components. Additionally, there was a content analysis of the comments from the surveys and the whole-class discussion. This analysis provided valuable insights to answer the first research question: what keeps the students from participating in $S T$. 
Having got the answer to the first research question at the pre-intervention stage, it was possible to consider the second research question of what teaching strategies should be used to increase the students' participation in ST at the opening stages of the classes.

The teacher's after-class writing and marginal notes were continued to be analysed; and the students' opinions about their progress were collected. They were analysed for general tendencies.

After the role plays, there was a tabulation of the registered cases of the strategies used, as well as the number of times the students chose a particular topic for an interaction.

Given additional time, it would have been reasonable to improve the chosen collection methods for the data related to student beliefs, for example, by organizing a final class discussion of the project with the students. Also, it would have been interesting to get the colleagues' opinions about their classroom ST experience, but unfortunately, only a few committed time to go through an interview. The sample size for this project is small $(n=9)$, so the data was only analysed for general trends and was not subjected to a statistical analysis.

In terms of triangulation, the study's credibility was strengthened through methods triangulation and time triangulation. In the context of this study, it refers to using more than one data source and data collection methods (observations, survey, and wholeclass discussion) and collecting the same data at different occasions.

\section{Discussion}

Next, some key findings associated with each research question will be addressed.

1. What factors keep students from participating in ST?

First of all, the students' input and the teacher's own self-reflection demonstrated that there were too many assumptions in the teaching; the major one was that there was an expectation that the students should automatically share the teacher's enthusiasm about ST. The students' beliefs about and attitudes towards ST had not been studied before this research project, and the question of whether the students are adequately equipped to make ST had not been addressed. This finding came from the survey and the discussion, both of which turned out to be indispensible in terms of welcoming and considering students' input.

Here are some extracts from what the students said:

"I always feel kind of awkward, when you confront me with your opening questions... like you are cornering me..."

"I do not really know what to say..."

"Other teachers do not expect us to make ST..."

"I'd love to participate, but I am not quite sure how..."

"It drives my Mom crazy when I try to make $S T$ with her in Russian. She says she feels I want something from her..."

Based on this input and some analysis of the reflective journal, it became possible to define what was wrong in terms of ST teaching in this class:

1. Almost no scaffolding for the students to participate in ST was provided.

2. The students did not fully understand why the teacher expected them to participate in classroom ST.

3. The ground rules for practicing ST as a social and linguistic skill had never been established. The students did not fully realize the different functions of the following structural components of the class: a greeting, a warm-up and a ST episode, as they were structured in the teacher's own understanding.

4. Given the students' background, and the kinds of teaching they were exposed at other classes, the expectations were unrealistic.

5. The repertoire of ST 'starters' needed to be revised. Instead of "cornering" the students with too direct questions about what and how, some 'friendlier' questions and comments had to be found, to which they would feel comfortable connecting and responding.

These issues were addressed while answering the second research question.

2. What teaching strategies should a teacher employ to increase students' participation in ST at the opening stages of the classes?

The initial literature review and the primary data have proposed a hypothesis that regular practice of ST at the opening stage of the class, can change the students' attitudes about ST.

In a small-scale teaching context like the author's, this hypothesis was confirmed, which became clear from the content analysis of the comments found in the students' logs, in the teacher's own observations, the classroom ST episodes, and in how the final role plays went.

A certain trend was noticed: when a student managed to sustain the ST for 2-3 exchanges, this was when he/ she made an entry in the logs. Since the course book strongly emphasizes the need to justify whatever one says/ writes with an example or an explanation, it was pleasant to see this critical thinking mechanism was realized in students' ST logs. 
In fact, their reflections gave a pretty round picture of what had changed and what was happening. Below are some of the illustrative extracts from the students' writing about ST:

Student 1: I liked how my small talk evolved today. I managed to make a comment about my yesterday's Philosophy class, and the teacher asked me an extra question, and I could answer it. I think this is because I have prepared in advance. I was expecting this question because the teacher knows that this is a hard class for our group this semester and she regularly uses this topic for small talk. Next time, I will prepare something else.

Student 2: The teacher started with a compliment about my new hairstyle today. I was glad she has mentioned it, because I like it myself. Last semester I would have just smiled awkwardly and said nothing. Now I know this is not appropriate, and although it was hard, there was a moment of hesitation, but then I remembered the mechanism we were talking about: "Tell me more, please! Give details!”, so I went like: “Thank you very much, I am glad you've noticed my new hairstyle. I did it because it was my Dad's birthday yesterday. I wanted to look nice". And then we talked about my Dad and his birthday party. Surprisingly, my classmates stepped in and started asking questions! That was great!

The content analysis of the ST episodes also demonstrates that the students became more selfaware about managing ST. This is true for both spontaneous classroom ST interactions (teacherstudents), and the set communicative situations (student-student). Below are two illustrations of these interactions with the teacher's comments on the ST moves and the language.

T: Any news?

S1: I went to Passport Office yesterday.

T: Passport Office? (shadowing, inviting for more information)

S1: Yes, I am 20 now, so I have to change my passport. (giving more information)

$\mathrm{T}$ : Oh... That must be an interesting procedure. (“That's..." comment)

S1: Interesting?!.... Not at all. (shadowing + more details)

$\mathrm{T}$ : Why not? (asking an extra question)

S1: My photos were ugly...and I spent an hour filling up the form several times. It bored me a lot. (complaining)

T: Well, now you can forget about it for a long time...until you are 45, I think. (offering sympathy)

S1: Thank you, that's comforting. ("That's ..." comment)

S5: I've always thought that winter is better than summer. (an implicit invitation either to comment or to ask an extra question)

S7: Interesting! What makes it so special to you? (comment + extra question)

S5: You know, I've always loved the winter's atmosphere the best. (giving more information)

S7: Same with me. (agreeing)

While these episodes might seem naive to many communication experts, it is possible to argue that they register two major changes. First of all, there was a change in the atmosphere: while at the initial stages of this study, silences, hesitations and pauses took most of the talk time, now it was obvious that the students were actually talking. Secondly, there was a definite change in the students' communicative behaviour: they were trying to build in the strategies they learned and practised, and because they now knew what could fill the conversation, they no longer diverted their eyes from those who were initiating ST, and they also did not expect somebody else to pull the weight, taking a very proactive and responsible role in sustaining the ST.

Overall, the teacher's observations also confirm the positive change. While the initial stage marginal comments registered her frustration at the students' unsatisfactory performance, within the intervention stage, and especially close to its end, her own perception of what was happening became more enthusiastic in tone. These notes also started to register the mechanism which had been practised in class, and how they found their way into spontaneous ST exchanges.

The final role plays were analysed based on the peer assessment of ST performance. While each individual assessment grid was analysed, it also seemed important to have a whole-group picture, which would demonstrate the students' utilization of the topics, appropriate for ST and the mechanisms which made it possible. Table 3 highlights the total number of instances when students made use of a certain ST mechanism and Table 4 registers the total number of their referring to a particular topic within STs.

All in all, given that there was practically no ST happening at the very beginning of the study, with a maximum of one unenthusiastic reply from a most emphatic student, now there was real participation and true attempts by almost all the students to utilize ST strategies.

The students' logs and their peer assessment appeared to confirm that utilizing ST in the opening stages of the classes may have a positive effect on students' willingness and ability to participate in ST. The skill was redefined throughout the project in value terms for the students' effective sociolinguistic functioning. Equally important, it proved to be an important part of the classroom talk. Without purposeful enforcing this element of the classroom talk into the classes, it would not have been possible to showcase that making ST is not just an exercise, 
Table 3

Final role play results: ST strategies at work

\begin{tabular}{lc}
\hline The mechanisms at play & $\begin{array}{c}\text { Total number of } \\
\text { observed instances }\end{array}$ \\
\hline shadowing & 15 \\
\hline asking an extra question & 21 \\
\hline $\begin{array}{l}\text { commenting on something that your } \\
\text { partner has said }\end{array}$ & 25 \\
\hline $\begin{array}{l}\text { commenting on something from the } \\
\text { actual, real-life context }\end{array}$ & 10 \\
\hline $\begin{array}{l}\text { verbalizing your agreement or disagree- } \\
\text { ment }\end{array}$ & 12 \\
\hline $\begin{array}{l}\text { complimenting } \\
\text { complaining }\end{array}$ & 16 \\
\hline
\end{tabular}

Table 4

Final role play results: ST topics at work

\begin{tabular}{lc}
\multicolumn{1}{c}{ The topic } & $\begin{array}{c}\text { Total number of } \\
\text { observed cases of } \\
\text { making ST around the } \\
\text { indicated topics }\end{array}$ \\
\hline the weather & 15 \\
\hline the surroundings & 11 \\
\hline traffic & 18 \\
\hline $\begin{array}{l}\text { how is school going (other classes, } \\
\text { homework, tests, exams, University } \\
\text { social life) }\end{array}$ & 14 \\
\hline $\begin{array}{l}\text { the weekends/vocations/ last night } \\
\text { TV programs from last night }\end{array}$ & 12 \\
\hline $\begin{array}{l}\text { recent concerts/ festivals/ soccer } \\
\text { matches, etc. }\end{array}$ & 6 \\
\hline $\begin{array}{l}\text { city news } \\
\text { common acquaintances and what } \\
\text { happened to them (exchanging } \\
\text { news) }\end{array}$ & 4 \\
\hline \begin{tabular}{l} 
health \\
\hline
\end{tabular} & 22 \\
\hline
\end{tabular}

but rather an integral part of unstructured meaningful communication between the teacher and the students, even if this communication is happening within the classroom walls.

The study finished up with a survey, where the students once again evaluated their perception of ST as a sociolinguistic phenomenon, as well as their own skills in managing ST. Table 5 shows the considerable change in the attitudes.

The major changes were in the students' perception of ST, and its function both in class (particularly through classroom talk) and beyond. With the change in the attitudes, there appeared a more self-aware attitude towards how to manage ST, and how to practise this skill within an EFL setting.
Table 5

Survey results: Pre-intervention and post-intervention stages $(n=9)$

\begin{tabular}{lcc}
\hline \multicolumn{1}{c}{ The statement } & $\begin{array}{c}\text { Pre-intervention } \\
\text { responses }\end{array}$ & $\begin{array}{c}\text { Post-interven- } \\
\text { tion responses }\end{array}$ \\
\hline $\begin{array}{l}\text { I understand why I } \\
\text { need to make ST in } \\
\text { class }\end{array}$ & 0 & 7 \\
\hline $\begin{array}{l}\text { I understand why } \\
\begin{array}{l}\text { I need to make ST } \\
\text { in a real-life social } \\
\text { situation }\end{array}\end{array}$ & 2 & 9 \\
\hline
\end{tabular}

\section{Classroom ST helps}

me to make progress

in practicing speak-

ing English

I have been taught

how to make ST on

several occasions

during my years of

studying English

I do not make ST

anywhere else, ex-

cept for this class

2

8

I just want to get

through with this

stage in class and

move on to what

really matters (e.g.,

reading, listening,

writing)

I very often just do

not know what to

say, and there is no

time to think it over

I am ready to initi-

ate ST myself

4

9

\section{Conclusion}

This action research project resulted in a number of positive outcomes. The most significant one is the students' improved ST profile. This change became possible when the students were urged to participate in ST as a routine. It was demonstrated that ST is a manageable and learnable skill, the one that has implications that go far beyond a classroom setting, and then the teacher provided constant scaffolding for the learning process. Classroom talk became the platform and the instrument that maximized the students' opportunities to practise ST, and ultimately, to function more effectively in a social setting.

Moreover, there was a lesson learned of how much can be gained from conducting group discussions about the current teaching/learning situations. The students seemed to appreciate being invited into the decision-making process about how to approach the ST 
practice in the classes. Therefore, it seems reasonable to plan to do more of such sessions, and this decision resonates with a CLT principle that students need to be aware of their own learning process.

\section{References}

Baber, A. (1991). Great connections, small talk and networking for businesspeople. Manassas Park, VA: Impact Publications.

Bamford, J. (2008). Strategies for the improvement of international students' academic and cultural experiences of studying in the UK. In Hospitality, Leisure, Sport and Tourism Network: Enhancing Series, Internationalisation (pp. 1-10). York, UK: Higher Education Academy.

Barron, A., \& Schneider, K. P. (2009). Variational pragmatics: Studying the impact of social factors on language use in interaction. Intercultural Pragmatics, 6(4), 425.

Bayles, R.(2009).Aninvestigation into politeness, small talk and gender. Innervate Leading Undergraduate Work in English Studies, 1, 10-17. Retrieved from http://www.nottingham.ac.uk/english/documents/ innervate/08-09/0809baylesaninvestigationintopol iteness.pdf

Carducci, B. J. (1999). The pocket guide to making successful small talk: How to talk to anyone anytime anywhere about anything. New Albany, IN: Pocket Guide Pub.

Coupland, J. (2003). Small talk: Social functions. Research on Language and Social Interaction, 36(1), 1-6.

Edwards, M., \& Csizér, K. (2004). Developing pragmatic competence in the EFL classroom. English Teaching Forum, 42(3), 16-21.

Fine, D. (2005). The fine art of small talk: How to start a conversation, keep it going, build networking skills - and leave a positive impression! New York, NY: Hyperion.

Fleming, C. (2013). It's the way you say it: Becoming articulate, well-spoken, and clear. San Francisco, CA: Berrett-Koehler Publishers.

Hadfield, J. (1996). Advanced communication games. Essex, UK: Addison Wesley Longman.

Hadfield, J. (1996). Intermediate communication games. Essex, UK: Addison Wesley Longman.

Jacobs, M., \& Farrell, T. (2001). Paradigm shift: Understanding and implementing change in second language education. TESL-EJ, 5(1). Retrieved March 6, 204 from http://tesl-ej.org/ej17/a1.html

Holmes, J. (2005). When ST is a big deal: Sociolinguistic challenges in the workplace. In M. H. Long (Ed.), Second Language Needs Analysis (pp. 344-371). Cambridge, UK: Cambridge University Press.

Koester, A. (2010). Workplace discourse. New York, NY: Continuum.

Littlewood, W. (1981). Communicative language teaching: An introduction. Cambridge, UK: Cambridge University Press.

Luk, J. (2004). The dynamics of classroom small talk. Issues in Applied Linguistics, 14(2), 115-132.

McCarthy, M. (2003). Talking back: 'Small' interactional response tokens in everyday conversation. In J. Coupland (Ed.), Research on Language in Social Interaction. Special Issue on ST, 36(1), 33-63.

Mehus, S. (2004, April). The micro-organization of taking a break: Transitions between task and nontask activities at work. In Proceedings of the Twelfth Annual Symposium about Language and Society (pp. 125-137). Austin, TX: University of Texas.

Mirivel, J. C., \& Tracy, K. (2005). Premeeting talk: An organizationally crucial form of talk. Research on Language and Social Interaction, 38(1), 1-34.

Ockenden, M. (1972). Situational dialogues. Essex, UK: Longman.

Richards, J. (2006). Communicative language teaching today. Cambridge, UK: Cambridge University Press.

Richards, J. (2008). Teaching listening and speaking: From theory to practice. Cambridge, UK: Cambridge University Press.

Sakamoto, B. (2010, June 19). A socializing game: Driver's seat (by Anne Hodgson). Retrieved from http://www.teachingvillage.org/2010/06/19/asocializing-game-drivers-seat-by-anne-hodgson/

Schneider, K. P. (2008). Small talk in England, Ireland, and the USA. Pragmatics and Beyond New Series, $178,99$.

Tannen, D. (1984). The pragmatics of cross-cultural communication. Applied Linguistics, 5(3), 189-195.

The Higher Education Academy. (n.d.). Case stories. Retrieved from http://www.heacademy.ac.uk/ resources/detail/internationalisation/teachinginternational-students-case-studies

Ur, P. (Ed.). (1992). Five-minute activities: A resource book of short activities. Cambridge, UK: Cambridge University Press.

Ur, P. (2013, August 23). Beginning and ending lessons [Online Discussion Group]. Retrieved from http:// www.cambridgeenglishteacher.org/discussions/ thread/1073

Westcombe, J. (2009, February 23). The small-talk game (or: Flies on the windscreen). Retrieved from http:// www.spotlight-online.de/teachers/try-it-out/ speaking/the-small-talk-game-or-flies-on-thewindscreen 